\title{
Growing Human Population \& Sustainable Development
}

\author{
Shubham Yadav \\ J.S. University, Shikohabad, India
}

\begin{abstract}
The 2030 Agenda for Sustainable Development, adopted by all United Nations Member States in 2015, provides a shared blueprint for peace and prosperity for people and the planet, now and into the future. No Poverty, Zero hunger, Health \& Wellness, Gender Equality, Clean Water, and many others have been kept on priority for development across world. But what plays a critical role in planning, execution, and success of these goals is "Resource Estimation \& Planning" and that in turn is dominated by the 'Human Population Trends' of different regions on globe.
\end{abstract}

Growing Human Population has been a challenge for all future-plans for sustainable development across globe and their success. The current paper highlights the close correlation between trends of growing human population and sustainable development

Key words: $\quad$ Population Demographics; Sustainable Development; UN-SDG2030

\section{Introduction}

The world population had surpassed the 7 billion mark in 2013 and has been projected to grow to over 9 billion by 2043 [8]. Human population of a region and its increasing or decreasing trend plays a critical role in planning and success of any development programs for the region. Growing human population demands more resources than usual planning and hereby sits in the core of all resource-crisis and raise challenges in sustainable development of the society.

Human population growth, population ageing and decline, as well as migration and urbanization of human population affect virtually each and every objective of development that are on top of national and global development agendas. It affects the consumption, production, employment, income distribution, poverty and social protections and every schemes of development. It also complicates every effort to ensure universal access to health, education, housing, sanitation, water, food and energy [8].

This is not much complex to understand that growing human population adds to energy consumption, carbon emissions, global warming, depreciation of forests, crisis of food and drinking water, and demand of every consumable resource.

In this span of 200 years, where the world population has increased by 6-times, this has increased the energy consumption to 35 times and carbon emissions to 20 times.
Despite technical advances in these figures, it remains to be debatable how exactly the increase of population or consumption of energy will exactly corelate to carbon emissions [7]. And the further question comes, how the growing human population is going to impact the sustainable development of state.

The world population was reported to be 6.1 billion in year 2000 and 7.2 billion in 2015 . These figures clearly show that human population growth is increasing at an accelerated pace and so is the respective consumption of environmental resources too.

\section{World Population Trend}

Figure -1 shows the time mapped world population graph as reported by worldometers.info/world-population

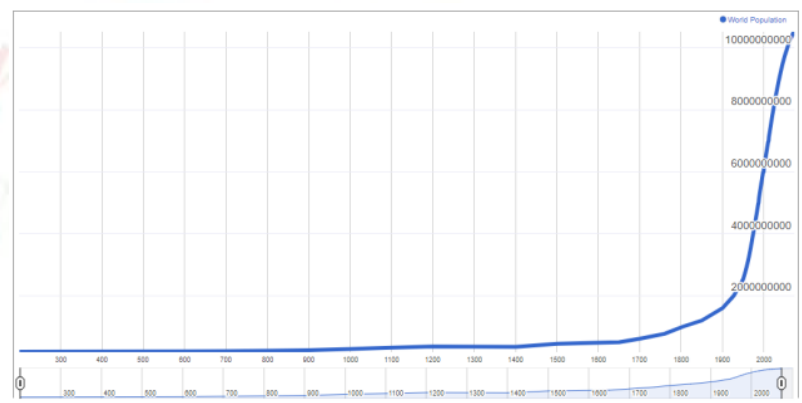

Figure 1: World Human Population Graph 
Figure - 2 shows a time mapped World Human Population Growth Rate as reported by World Bank till end of year 2017.

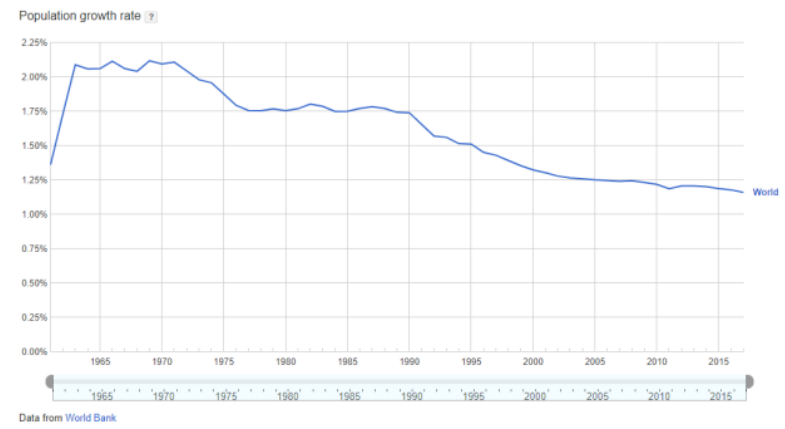

Figure 2: World Human Population Growth Rate

Figure - 3 shows a time mapped South-Asian Human Population Growth Rate as reported by World Bank till end of year 2017.

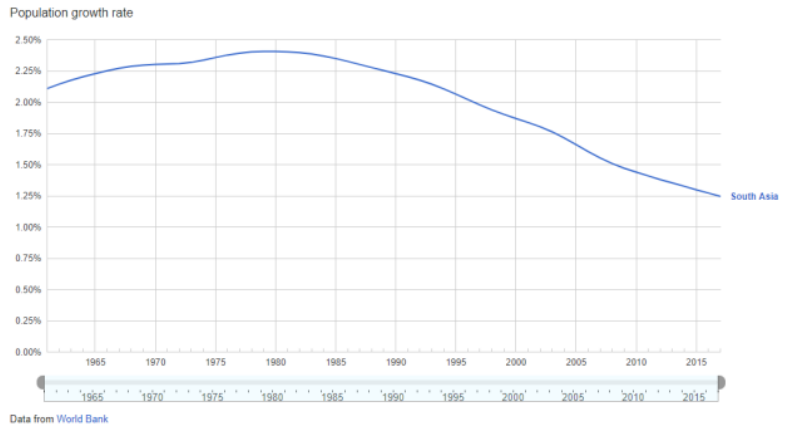

Figure 3: South-Asian Human Population Growth Rate

Figure -4 shows a time mapped Indian Human Population Growth Rate as reported by World Bank till end of year 2017.

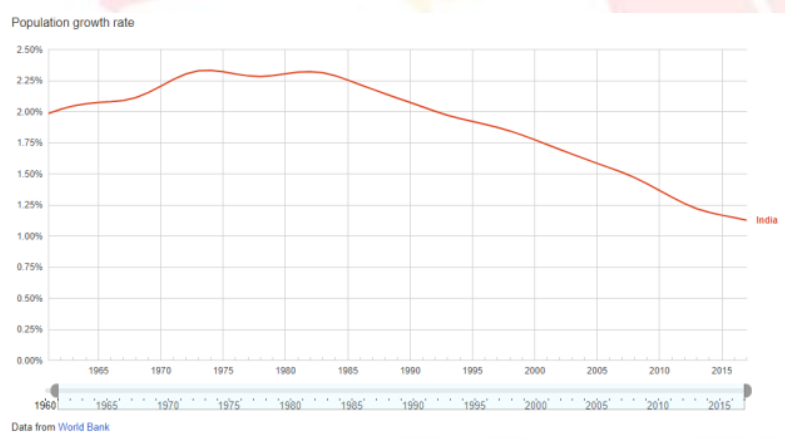

Figure 4: Indian Human Population Growth Rate

Figure - 5 shows a time mapped Comparative Human Population Growth Rate for World, South-Asia, and India, as reported by World Bank till end of year 2017.

Most contemporary estimates for the carrying capacity of the Earth under existing conditions are between 4 billion and 16 billion [10] and by this figure, human overpopulation on earth may have already occurred. Nevertheless, a concern has been created by the recent rapid increase in human population across globe. Different data and forecasting sources have expected the human population to reach a mark between 8 and
10.5 billion during the 10 -year span from 2040 to 2050 . In 2017, the United Nations has reportedly increased the medium variant projections to 9.8 billion for 2050 whereas for 2100 , it has been reported to be 11.2 billion. [1], [2], [3], [12].

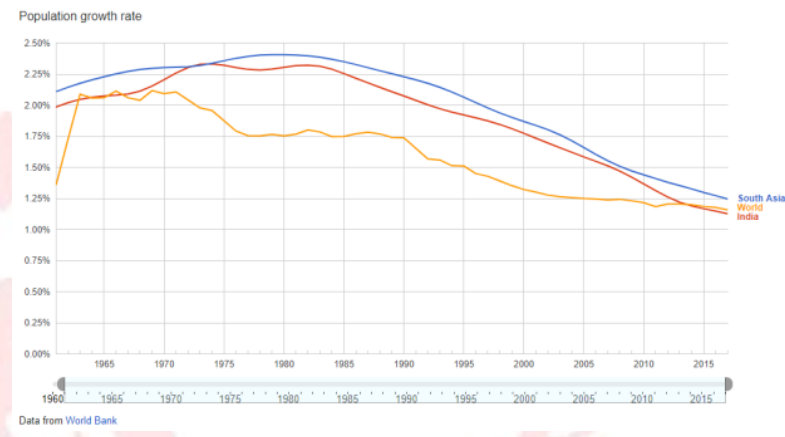

Figure 5: Comparative Human Population Growth Rate for World, South-Asia, and India

\section{Concept of Compounded Demand}

The growing human population is the major threat to the success of any plans of meeting the resource requirements of the population of any region of the world or on entire globe. There is a need to plan long-lasting uses of resources and also the plans about optimizing the usage.

There can be plans about preservation of resources and its appropriate distribution uniformly among all humankind as per their needs. But unfortunately, there is no means to reduce the compounded demand of resources. Here the compounded demand means to the aggregated demand of all resources meant for one type of use, e.g. fuel. There may be multiple fuel resources available viz. Petrol, Gas, Fossils, etc. and one may be able to replace the demand of other in given conditions. But compound demand of fuel still remains the same and cannot be reduced.

\section{Impact on Sustainable Development}

Figure - 5 depicts that the Sustainable Development is an integrated concept of economic development, environmental development, and development of the society. The compounded result of all these three gives a sustainable development to the region.

Sustainable development of a region needs rigorous planning of focus areas, resources requirements, distribution systems, dedicated efforts, genuine sense of responsibility, and honesty in implementation of plans. Sustainable Development is not merely the development of present population but is a development to sustain for future generations too.

Based on differences in rate of growth of human populations in different countries of world, this is not complex to understand that there would be a significant difference 


\section{Yinternational Research Journa}

p-ISSN 2202-2821 e-ISSN 1839-6518 (Australian ISSN Agency)

between present and future demographic distribution of populations across the globe. Majority of the human population present and in near future belongs to developing countries.

\section{Components of Sustainable Development}

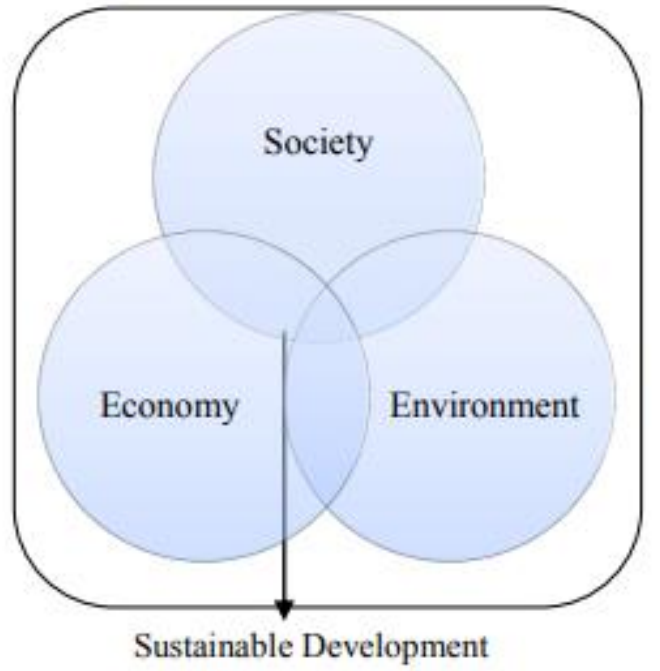

Source: Peeters, 2012: 293

Figure 6: Integration Concept of Sustainable Development Growth of Human population affects almost every plans and forecasts of sustainable development.

This is much clear that world human population is increasing at an exponential rate and earth is accelerating to the saturation of its capacity to serve to such huge human population. Two major impacts of such large human population on earth are:

- Accelerated consumption of resources like land, water, air, food, fuels, and minerals.

- Accelerated production of wastes, more toxification of environment, and global warming.

\section{A. Environmental Impacts}

Studies have revealed that growing human population have given depreciating impacts on nature and environment on earth. Growing Human population is going to badly hit the Sustainable Development for all parameters linked to earth environment including clean air, drinking water, healthy food, resources of energy, and climate inadaptability.

\section{B. Social Impacts}

No doubt, when there will be a scarcity of resources, fights of survival will take its most ugly shapes. Human will fight among themselves for capturing of required resources for them, for their families, and for their communities.
Growing Human population is going to badly hit the Sustainable Development for all parameters linked to social life of human including employment, poverty, health \& wellbeing, education, and social equality.

\section{Human as new Geophysical Force}

The impact of so many human on the planet has resulted in some scientists coining a new term to describe the current era - the Anthropocene epoch. While in most of the previous geological epochs, the time periods have been defined by various geological and climate processes, the proposed Anthropecene period is known for the dominant influence of humans and impacts of their activities on the environment of the planet. In essence, humans are a new global geophysical force. [6]

\section{Opportunities for Sustainable Development by Growing Human Population}

Growing human population and population dynamics do not only pose challenges for sustainable development, but they also provide important opportunities for more sustainable development.

If responsible-consumption plans are drafted and implemented appropriately, the growing human population may be opportune for improving production capacity. Furthermore, if planned and executed smartly, the growing human population may be opportune for Industry, Innovation, and Infrastructure creation. By development of sustainable communities and smart cities, the growing population can give optimal outcomes in the form of mutual collaborations and making human lives better. Urbanization can be an important enabler of social and economic development.

\section{Conclusion}

World Human Population is growing at exponential rates and so is increasing the pressure on resources on earth. Earth is reaching to its capacity of serving to human population with the available resources and there is a need of serious efforts towards optimal plans for sustainable development.

Compounded Demand of resources cannot be decreased with increasing human population.

Growing Human Population where increases challenges in sustainable development in most of the plans linked to environment and social development, it also creates opportunities in the areas of innovation, infrastructure, and other areas if sustainable development is planned and executed appropriately. 


\section{References}

[1]. Census.gov. (2010), "International Data Base (IDB) - World Population". 28 June 2010. Archived from the original on 7 July 2010. Retrieved 1 August 2010.

[2]. PDDESA-UNS (2009), "World Population Prospects: The 2008 Revision". Population Division of the Department of Economic and Social Affairs of the United Nations Secretariat.

[3]. PDDESA-UNS (2017), "World population projected to reach 9.8 billion in 2050, and 11.2 billion in 2100". Population Division of the Department of Economic and Social Affairs of the United Nations Secretariat.

[4]. Pinto Oshma Rosette (2015), "Effect of Global Recession on Indian Realty Sector and its Future Developments", IARS'International Research Journal, Vol. 5, No. 2, 2015 (URL:https://researth.iars.info/index.php/curie/artic le/download/49/48)

[5]. Robert Engelman (2009), "Population \& Sustainability", Scientific American Special Editions 19, 2s, pg 22-29, doi:10.1038/scientificamericanearth0609-22; URL: https://www.scientificamerican.com/article/populationand-sustainability/ Retrieved 10 August 2017

[6]. Stephen Dovers, Colin Butler (2015), "Population and environment: a global challenge", Australian Academy of Science,

URL: https://www.science.org.au/curious/earthenvironment/population-environment, Retrieved 15 December 2017

[7]. Taner Güney. (2017). POPULATION GROWTH AND SUSTAINABLE DEVELOPMENT IN DEVELOPED-DEVELOPING COUNTRIES: AN IV(2SLS) APPROACH. 22. 1255-1277.

URL:

https://www.researchgate.net/publication/321167892 Retrieved 1 August 2017

[8]. United Nations Population Fund (2013), "Sustainable Development and Population Dynamics: Placing People at the Centre", Statement by Anne-Birgitte Albrectsen, UNFPA's Deputy Executive Director of Management, at the Open Working Group on Sustainable Development Goals; URL: https://www.unfpa.org/press/sustainabledevelopment-and-population-dynamics-placingpeople-centre Retrieved 10 August 2017

[9]. Venus Upadhayaya (2017), "Emotional Dynamics of Action and Core Involvement: A new theoretical perspective for designing development strategies in schools", IARS'International Research Journal, Vol. 7, No. 2, 2017 (URL: https://researth.iars.info/index.php/curie/article/do wnload/79/66)

[10]. Wikipedia (2017), "Human overpopulation", URL: https://en.wikipedia.org/wiki/Human_overpopulation, Retrieved 05 January 2018

[11]. Worldometer (2017), "World Population Statistics", URL: https://www.worldometers.info/world-population/, Retrieved 05 October 2017

[12]. Worldometers (2017), "World Population Clock Worldometers". Worldometers.info. Retrieved 1 August 2017. 